\title{
How Comprehensive Medication Management Contributes to Foundational Elements of Primary Care
}

\author{
Kylee A. Funk, PharmD, Lindsay A. Sorge, PharmD, MPH, Andrew W. Bazemore, MD, MPH, \\ Todd D. Sorensen, PharmD, Mary T. Roth McClurg, PharmD, MHS, and \\ Jennifer K. Carroll, $M D, M P H$
}

Pharmacists are more often being recognized as a critical component of the primary care team.

Previous literature has not clearly made the connection to how pharmacists and comprehensive medication management (CMM) contribute to recognized foundational elements of primary care. In this reflection, we examine how the delivery of CMM both supports and aligns with Starfield's 4 Cs of Primary Care. We illustrate how the delivery of CMM supports first contact through increased provider access, continuity through empanelment, comprehensiveness by addressing unmet medication needs, and coordination through collaborating with the primary care team and broader team. The provision of CMM addresses critical unmet medication-related needs in primary care and is aligned with the foundational elements of primary care. ( $\mathrm{J}$ Am Board Fam Med 2021;34:420-423.)

Keywords: Comprehensive Health Care, Medication Therapy Management, Patient Care Team, Pharmacists, Primary Health Care, Workforce

Barbara Starfield's 4 Cs of Primary Care-first contact, continuity, comprehensiveness, and coordination-are thought to explain the positive effects of primary care on cost, quality, and equity. ${ }^{1,2}$ Many scholars have built on Starfield's characterization of the $4 \mathrm{Cs}$, including Bodenheimer and others, to further elucidate the essential components of primary care $^{3}$ and the teams that are critical to its effective provision. $^{4-6}$ Due to evolving payment models and growing patient complexity, the necessity of teambased care models is greater than ever before. Pharmacists are increasingly recognized as significant contributors to primary care teams, but little has been written about their roles in delivering on

This article was externally peer reviewed.

Submitted 12 September 2019; revised 27 August 2020; accepted 31 August 2020.

From the University of Minnesota College of Pharmacy, Minneapolis (KAF, LAS, TDS); American Board of Family Medicine, Lexington, KY (AWB); University of North Carolina Eshelman School of Pharmacy, Chapel Hill (MTRM); American Academy of Family Physicians National Research Network, Leawood, KS (JKC); Center for Professionalism \& Value in Health Care, Washington, DC (AWB).

Funding: The American College of Clinical Pharmacy (ACCP) and the ACCP Foundation Grant Enhancing Performance in Primary Care Medical Practice through Implementation of Comprehensive Medication Management. Conflict of interest: None. the foundational elements of primary care as described by Starfield. We examine in this reflection the connection between Starfield's framework of primary care, pharmacists, and comprehensive medication management (CMM).

CMM, the practice of ensuring that each medication a patient is taking is currently indicated, effective for the disease it is treating, safe given the patient's other medications and conditions, and best suited for the individual patient, holds significant promise as an effective, team-based intervention to optimize medication use in practice. ${ }^{7,8}$ Current accreditation standards ensure pharmacists are trained to apply a standard patient care process and serve as an integral member of the health care team in providing CMM. ${ }^{9}$ The service of CMM is distinct from traditional services of providing safe and effective distribution of medications and typically does not include dispensing of medications but rather is often provided within a medical clinic or other setting where the pharmacist conducts in-person evaluations and follow-up visits with the patient to

Corresponding author: Kylee A. Funk, PharmD, College of Pharmacy, Room 50130 WDH, 1332A, 308 Harvard St. SE, Minneapolis, MN 55455 (E-mail: kafunk@umn.edu). 
Complex patient case: RF is a 72-year-old male who lives with his wife. He has limited financial resources and limited means of transportation. RF has a history of poorly controlled type 2 diabetes, heart failure, dementia, depression, chronic obstructive pulmonary disease, and pain. He often has difficulty affording medications. He recently had an emergency room visit as a result of a fall.

\begin{tabular}{|c|c|c|}
\hline 4 Cs Pillar & $\begin{array}{c}\text { How CMM Supports Primary Care } \\
\text { in Achieving the } 4 \text { Cs }\end{array}$ & $\begin{array}{c}\text { How Practice of CMM Aligns with } \\
\text { the } 4 \text { Cs of Primary Care }\end{array}$ \\
\hline First contact & $\begin{array}{l}\mathrm{RF} \text { and his wife noted blood sugar readings over the } \\
\text { past month are elevated. He scheduled an } \\
\text { appointment with a pharmacist providing CMM } \\
\text { who he has met with in the past. This increases } \\
\text { access and "contact" to the health care team for RF. }\end{array}$ & $\begin{array}{l}\text { After RF's hospitalization, his wife sent the pharmacist } \\
\text { providing CMM in the clinic a message to clarify if a } \\
\text { symptom he was experiencing may be a side effect of } \\
\text { a new medication. }\end{array}$ \\
\hline Continuity & $\begin{array}{l}\text { RF was referred to } \mathrm{CMM} \text { services as a part of a } \\
\text { providers' panel of patients not meeting diabetes } \\
\text { goals. }\end{array}$ & $\begin{array}{l}\text { The pharmacist providing CMM for RF will continue } \\
\text { to follow up with the patient until the patient's goals } \\
\text { are achieved. }\end{array}$ \\
\hline Comprehensiveness & $\begin{array}{l}\text { Although RF was referred to CMM services because } \\
\text { he was not meeting diabetes goals, the pharmacist } \\
\text { providing CMM will comprehensively review all } \\
\text { medications the patient is taking and help resolve } \\
\text { all issues, such as inhaler affordability, not only } \\
\text { concerns related to diabetes medications. }\end{array}$ & $\begin{array}{l}\text { When RF started to follow up with CMM services, the } \\
\text { pharmacist identified that he had difficulty taking } \\
\text { twice-daily medications and was able to work with } \\
\text { the care team to create a regimen with more once- } \\
\text { daily medications. This helped RF to better meet his } \\
\text { health goals. }\end{array}$ \\
\hline Coordination & $\begin{array}{l}\text { During RF's CMM appointment, it became unclear } \\
\text { which medications RF was actually taking. To } \\
\text { clarify the current medication regimen, the } \\
\text { pharmacist coordinated with RF, his wife, RF's } \\
\text { pharmacy, and his cardiology team in a different } \\
\text { health system. }\end{array}$ & $\begin{array}{l}\text { When the pharmacist was working with RF to help } \\
\text { manage his congestive heart failure, the pharmacist, } \\
\text { working in collaboration with the patient's pain } \\
\text { management provider, decreased nonsteroidal anti- } \\
\text { inflammatory drug use and found an alternative, } \\
\text { safer treatment option. }\end{array}$ \\
\hline
\end{tabular}

optimize his/her medication use in collaboration with other members of the health care team. ${ }^{10}$

The practice of CMM by pharmacists is guided by 5 philosophical tenets: (1) the practice is rooted in meeting a societal need, (2) the practitioner assumes responsibility for optimizing medication use, (3) care is provided through a patient-centered approach, (4) care is supported by an ongoing patient-pharmacist relationship, and (5) practitioners work as a collaborative member of the health care team. ${ }^{11}$ The service of CMM, when delivered with fidelity, ${ }^{8}$ has demonstrated positive effects on the Quadruple Aim of better health, better patient experience, lower cost, and joy in practice. Prior studies have demonstrated impact on clinical measures such as A1c and diabetes-related quality measures ${ }^{12}$ and hypertension ${ }^{13}$ and health resource use. ${ }^{14}$ The impact on provider ${ }^{15}$ and patient experience is positive. ${ }^{16,17}$ And CMM delivered as part of an interprofessional team has demonstrated a positive financial return on investment. ${ }^{7,18}$ Previous work has pointed out how medication therapy management (MTM), which is a similar but less well defined and often more narrowly focused intervention than CMM, supports the primary care function. ${ }^{19}$

To further understand the contribution of CMM services to team-based care, we examined parallels between foundational aspects of CMM and the 4 Cs. We specifically considered CMM delivered by a pharmacist embedded in a primary care clinic. We considered the 5 philosophical tenets previously discussed ${ }^{11}$ as well as practice management aspects of CMM pharmacists. In this reflection, we establish (1) how, if properly implemented, CMM can support and advance each of the foundational elements of primary care, and (2) how the practice of CMM aligns with each of these pillars. Table 1 provides an example of the findings we describe below.

When describing first contact, Starfield notes, "there should be one particular place or health care provider serving as a point of entry into the health system each time a new problem is experienced." The delivery of CMM supports first contact by increasing provider access. Because the pharmacist assumes responsibility for some of the longitudinal management of patients with chronic illness, primary care providers (PCPs) realize an increased capacity for initial and urgent visits. ${ }^{15}$ The service of CMM also aligns with the pillar of first contact because the pharmacist providing CMM assumes the responsibility for optimizing medication use. When an established patient has an ongoing relationship with a pharmacist as a part of the primary care team, the 
patient knows that first contact for medication concerns and needs could be the pharmacist in the clinic.

Continuity is the second pillar and is described as "individuals use their primary source of care over time for most of their health care needs." Continuity of care is promoted through population health management. Pharmacists, as integrated members of the health care team, partner with PCPs to identify patients and groups most in need of CMM to optimize medications. Longitudinal relationships between patients and pharmacists enhance the value of overall primary care continuity. Pharmacists providing CMM align with continuity because they ensure that they are providing care through an ongoing patient-pharmacist relationship via follow-up visits. In addition, to understand the population receiving CMM and ensure they are targeting patients most in need, the pharmacist identifies those patients most in need of $\mathrm{CMM}$ and can follow those patients over time who are receiving CMM. Patients benefit from this ongoing relationship with their pharmacist. In fact, a personal relationship with a pharmacist has been identified as a top predictor of medication adherence for patients. ${ }^{20}$

The third pillar, comprebensiveness, is described as "the extent to which primary care practitioners provided a broader range of services rather than making referrals to specialists for those services" ${ }^{2}$ To be fully comprehensive, primary care must address all medical needs of a patient, which include medication optimization. Pharmacists providing CMM support comprehensiveness through taking responsibility to address the societal need of optimizing medication use, adding additional, focused expertise to the primary care team. In prior interviews with PCPs, informants have suggested that CMM can lead to a reduction in calls and referrals to specialists, a concept requiring more evaluation but with the potential to expand primary care team scope and impact unnecessary care use. ${ }^{15}$ In addition, the service of CMM aligns with the pillar of comprehensive because pharmacists approach the patient holistically and assume responsibility for optimizing all medications a patient is taking.

The last pillar is coordination and it is noted that "primary care practice must integrate all aspects of care when patients must be seen elsewhere" Pharmacists providing CMM support primary care in coordination through working as a collaborative member of the health care team. In this role, the pharmacist takes part in obtaining past information (eg, medication histories, medication reconciliation) that help inform current treatment and assume responsibility for the coordination of care around optimization of the patient's medications. This coordination role benefits the patients. For example, CMM provided after hospital stays has demonstrated decreased readmissions. ${ }^{14,21}$ Decreased readmissions are likely in part driven by coordination efforts and may be due to the support that the CMM pharmacist is providing the primary care team through coordinating with the hospital care team and may also be due to the direct contributions of the pharmacist. Last, CMM aligns with coordination through collaborating with the team, both in the primary care practice and the broader team including specialists and the patient's community pharmacy.

As the health care community seeks to achieve the Quadruple Aim, it is critical to consider interprofessional practices in primary care. ${ }^{22}$ Pharmacists providing CMM both support and provide services that align with each of the $4 \mathrm{Cs}$ of primary care. Given this role, CMM holds significant promise as a clinical service embedded in primary care practices provided by pharmacists working in collaboration with the patient and the health care team to optimize medication use and advance patient care.

To see this article online, please go to: http://jabfm.org/content/ 34/2/420.full.

\section{References}

1. Starfield B. Primary care: concept, evaluation, and policy. New York: Oxford University Press; 1992.

2. Starfield B, Shi L, Macinko J. Contribution of primary care to health systems and health. Milbank Q 2005;83:457-502.

3. Bodenheimer T, Ghorob A, Willard-Grace R, Grumbach K. The 10 building blocks of high-performing primary care. Ann Fam Med 2014;12:166-71.

4. Institute of Medicine. Primary care: America's health in a new era. Washington, DC: National Academies Press; 1996.

5. International Conference on Primary Health Care. Declaration of Alma-Ata. WHO Chron. 1978;32: 428-30.

6. Smith M, Bates DW, Bodenheimer TS. Pharmacists belong in accountable care organizations and integrated care teams. Health Aff (Millwood) 2013; 32:1963-70.

7. Webb E, Strand L, McInnis T. The patient-centered medical home: integrating comprehensive medication 
management to optimize patient outcomes resource guide. 2nd ed. Washington, DC: Patient-Centered Primary Care Collaborative; 2012.

8. CMM in Primary Care Research Team. The patient care process for delivering comprehensive medication management (CMM): optimizing medication use in patient-centered, team-based care settings. 2018. Available from: http://www.accp.com/ cmm_care_process. Accessed November 11, 2018.

9. Accreditation Council of Pharmacy Education. Accreditation standards and key elements for the professional program leading to the doctor of pharmacy degree. 2015. Available from: https://www. acpe-accredit.org/pdf/Standards2016FINAL.pdf. Accessed January 22, 2019.

10. McBane SE, Dopp AL, Abe A, American College of Clinical Pharmacy, et al. Collaborative drug therapy management and comprehensive medication management-2015. Pharmacotherapy. 2015;35:e39-e50.

11. Pestka DL, Sorge LA, McClurg MR, Sorensen TD. The philosophy of practice for comprehensive medication management: evaluating its meaning and application by practitioners. Pharmacotherapy 2018;38:69-79.

12. Brummel A, Lustig A, Westrich K, et al. Best practices: improving patient outcomes and costs in an ACO through comprehensive medication therapy management. JMCP 2014;20:1152-8.

13. Margolis KL, Asche SE, Bergdall AR, et al. Effect of home blood pressure telemonitoring and pharmacist management on blood pressure control: a cluster randomized clinical trial. JAMA 2013;310:46-56.

14. Budlong H, Brummel A, Rhodes A, Nici H. Impact of comprehensive medication management on hospital readmission rates. Popul Health Manag 2018;21:395-400.

15. Funk KA, Pestka DL, McClurg MR, Carroll J, Sorensen TD. Primary care providers believe that comprehensive medication management improves their work-life. J Am Board Fam Med 2019;32:462-73.

16. Kim S, Martin MT, Pierce AL, Zueger P. Satisfaction with medication therapy management services at a university ambulatory care clinic. J Pharm Pract 2016;29:199-205.

17. Ramalho de Oliveira D, Brummel AR, Miller DB. Medication therapy management: 10 years of experience in a large integrated health care system. J Manag Care Pharm 2010;16:185-95.

18. Isetts $\mathrm{BJ}$, Schondelmeyer SW, Artz MB, et al. Clinical and economic outcomes of medication therapy management services: the Minnesota experience. J Am Pharm Assoc 2008;48:203-11.

19. Olayiwola JN, Bodenheimer T, Dubé K, WillardGrace R, Grumbach K. Facilitating care integration in community health centers: a conceptual framework and literature review on best practices for integration into the medical neighborhood. UCSF Center for Excellence in Primary Care. Blue Shield of California Foundation Report. 2014. Available from: https://www.blueshieldcafoundation.org/sites/ default/files/publications/downloadable/Executive_ Summary_Facilitating_Care_Integration_Mar_2014. pdf. Accessed February 4, 2019.

20. National Community Pharmacists Association. Medication adherence in America: A national report. 2013. Available from: http://www. ncpanet. org/pdf/reportcard/adherencereportcard_abridged. pdf. Accessed December 11, 2013.

21. Cavanaugh JJ, Jones CD, Embree G, et al. Implementation science workshop: primary carebased multidisciplinary readmission prevention program. J Gen Intern Med 2014;29:798-804.

22. Bodenheimer T, Sinsky C. From triple to quadruple aim: care of the patient requires care of the provider. Ann Fam Med 2014;12:573-6. 